\title{
Intestinal pseudo-obstruction: The massive abdomen and the red herring
}

P Naidoo, S Schwartz, S Murphy, R D Mohanlal, H Greeves

A 13-year-old boy presented with a 1-year history of a gradually distending abdomen that was associated with constitutional symptoms, haematemesis and haematochezia that were exacerbated after taking traditional medicament. Admissions for similar episodes when he was 4 and 9 years old had yielded no diagnosis. A previous non-full-thickness rectal biopsy reported nonspecific changes. He was markedly cachexic with a grossly distended abdomen (Fig. 1) that was difficult to palpate. Shifting dullness was elicited and the flanks were dull. There was central hyper-resonance on percussion. Rectal examination was normal.

An X-ray of the abdomen revealed a grossly distended large intestine. Ultrasound showed increased ascitic fluid. A total colectomy with an ileostomy was performed. Histological examination of the colon (Fig. 2) was consistent with a diagnosis of hollow viscus myopathy. The patient died after a second laparotomy.

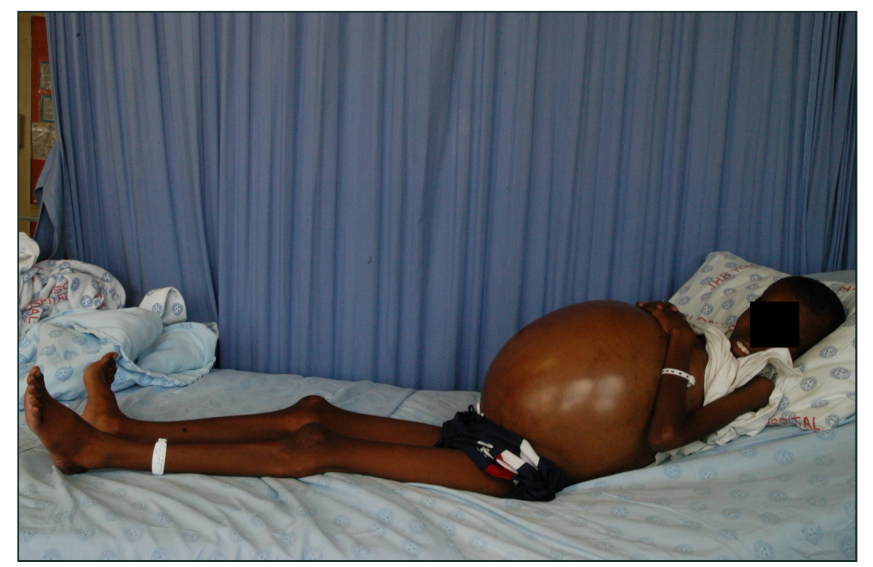

Fig. 1. Child with grossly distended abdomen.

Drs Naidoo, Schwartz and Murphy work in the Department of Paediatrics; Dr Mohanlal in the Department of Anatomical Pathology; and Dr Greeves in the Department of Paediatric Surgery, University of the Witwatersrand, Johannesburg.

Corresponding author: P Naidoo (poobalan1naidoo@yahoo.com)

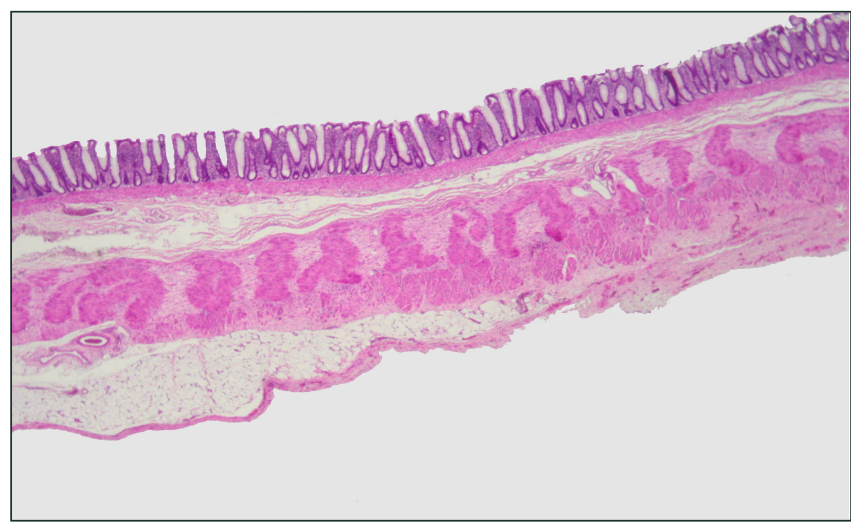

Fig. 2. Full-thickness large bowel showing severe fibrosis involving muscularis propria $(2 \mathrm{X})$.

\section{Discussion}

Chronic intestinal pseudo-obstruction (CIPO) is a rare, severe syndrome with impaired gastro-intestinal motility leading to functional obstruction resembling mechanical obstruction. It usually affects elderly people with underlying co-morbidities, and early recognition and appropriate management are essential to reduce life-threatening complications. ${ }^{1}$ The condition may be idiopathic or secondary to other conditions. Most cases are sporadic. Familial forms with either dominant or recessive autosomal inheritance have been described. Histologically, it is classified into neuropathies, mesenchymopathies and myopathies, according to the predominant involvement of enteric neurons, interstitial cells of Cajal or smooth-muscle cells, respectively. ${ }^{2}$ Hollow visceral myopathy (HVM) is a myopathic cause of CIPO.

HVM is a rare clinical entity characterised by impaired intestinal function and motility secondary to a smooth-muscle defect. ${ }^{3,4}$ Familial visceral myopathy is the most common type, with an autosomal dominant or recessive inheritance. ${ }^{5}$ Any part of the gastro-intestinal tract, and occasionally the urinary tract, may be involved. Presenting symptoms may be gastro-intestinal, ranging from abdominal pain and bloating to constipation or diarrhoea; or urological, ranging from recurrent urinary tract infections to urinary retention. ${ }^{4}$

A previous non-full-thickness biopsy did not identify any pathological changes. However, a full-thickness biopsy after colectomy identified pathology confirming that full-thickness biopsy is superior. ${ }^{6}$ 
This case was challenging because of the long duration, presence of constitutional symptoms, recent ingestion of traditional medicament, shifting dullness and dullness in the flanks on clinical examination, previous non-significant rectal biopsy, ascites revealed on ultrasound examination, and unhelpful laboratory investigations.
1. De Giorgio R, Knowles CH. Acute colonic pseudo-obstruction. Br J Surg 2009; 96(3): 229-239.

Antonucci A, Fronzoni L, Cogliandro L, et al. Chronic intestinal pseudo-obstruction. World J Gastroenterol 2008; 14(19): 2953-2961.

Isaacson C, Wainwright HC, Hamilton DG, et al. Hollow visceral myopathy in black South Africans. A report of 14 cases. S Afr Med J 1985; 67(25): 1015-1017.

4. Ghavamian R, Wilcox DT, Duffy PG, et al. The urological manifestations of hollow Ghavamian R, Wilcox DT, Duffy PG, et al. The urological r
visceral myopathy in children. J Urol 1997; 158: 1286-1290.

5. Jones SC, Dixon MF, Lintott DJ, et al. Familial visceral myopathy; a family with involvement of four generations. Dig Dis Sci 1992; 37: 464

6. Arslan M, Bayraktar Y, Oksuzoglu G, et al. Four cases with chronic intestinal pseudoobstruction due to hollow visceral myopathy. Hepatogastroenterology 1999; 46(25): 349-352.

\title{
CLINICAL IMAGES
}

\section{Partial flap avulsion following refractive surgery}

\author{
Roland R Berger, M D Williams, Clive A Novis
}

Refractive surgery, mainly laser in situ keratomileusis (LASIK), is widely used to correct refractive errors, mainly myopia. It consists of producing a corneal flap, ablating the underlying corneal stroma using laser energy, and repositioning the flap without suturing it to the underlying stroma.

A 58-year-old man presented with blurred vision, pain and photophobia after suffering a minor injury on his right eye from a tree branch. He had had LASIK procedures 13 years ago for both eyes. The eye was congested, there was corneal fluorescein staining, and the corneal flap was partially detached and scrolled up (Fig. 1).

Under local sub-conjunctival anaesthesia the flap was irrigated, cleaned, repositioned and sutured. Methylprednisolone and gentamicin were injected subconjunctivally, and the eye was closed for 24 hours. The following day the eye was quiet with a visual acuity of $6 / 9$ and the subsequent course was uneventful.

After a LASIK procedure the flap adheres to the corneal stroma because of the action of the endothelial pump and because the epithelium grows over the flap's margin. Scarring

Roland R Berger, MD (Padova), Specialist in Ophthalmology (Tel-Aviv), is Senior Consultant at Tambo Memorial Hospital in Boksburg. His main interest is ophthalmic trauma.

Melissa D Williams, $M B B C h$, is doing her community service at the same hospital.

Clive A Novis, MB BCh, FCS (Ophthalmology), is in private practice. His main interests are cataract and refractive surgery.

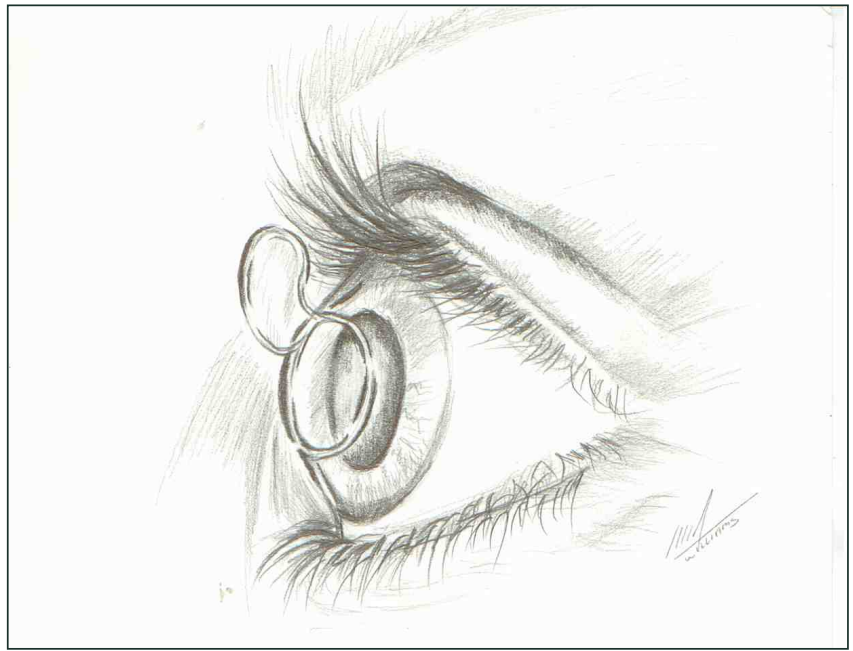

Fig. 1. Schematic representation of the avulsed epithelial flap.

and fibrosis occur only at the flap's margin. ${ }^{1}$ Early and late complications are mainly haloes, glare, star-burst and dry eye. A dreaded complication is corneal ectasia. ${ }^{2}$

Traumatic dislocation has been reported after 10 days, ${ }^{3} 1$ year ${ }^{4}$ and 3 years and 5 months. ${ }^{5}$ Our report is the first to indicate the possibility of weak adhesion of the flap after a much longer time, i.e. 13 years.

\section{References}

Ivarsen A, Laurgern T, Moller-Petersen T. Characterisation of corneal fibrotic wound repair at the LASIK flap margin. Br J Ophthamol 2003; 87(10): 1272-1278.

2. Piccoli P, Gomes AAC, Piccoli FVA. Corneal ectasia detected 32 months after LASIK for correction of myopia and asymmetric astigmatism. J Catar Ref Surg 2003; 29(3): 1222-1225.

Melki SA, Talamo JH, Demetriades AM. Late traumatic dislocation of laser in situ Melki SA, Talamo JH, Demetriades AM. Late traumatic dislocation of
keratomileusis corneal flaps. Ophthalmology 2000; 107(12): 2136-2139.

Tai M-C, Chen C-H, Chang C-J. Late traumatic dislocation of Lasik corneal flaps. J Med Sci Tai M-C, Chen C-H,
2003; 23(3): $165-166$.

5. Tetz M, Werner L, Muller M, Dietze U. Late traumatic lasic flap loss during contact sport. J Catar Ref Surg 2007; 33(7): 1332-1335. 